\title{
Diversidad de prácticas religiosas en las villas de la ciudad de Buenos Aires
}

\author{
Ana Lourdes SuÁrez*
}

IsABEL GATTI**

* Ph.D. en Sociología por la Universidad de California San Diego. CONICET/Universidad Católica Argentina.

** Investigadora en el Instituto de Investigaciones Facultad de Ciencias Sociales de la Universidad Católica Argentina en el Programa Condiciones de Vida y Religión. Universidad Católica Argentina. Correo electrónico: analourdessuarez@gmail.com

Fecha de recepción: 22/01/18. Fecha de aceptación: 09/05/18 


\title{
Diversidad de prácticas religiosas en las villas de la ciudad de Buenos Aires
}

\section{RESUMEN}

El trabajo describe y analiza la diversidad de prácticas religiosas de habitantes de villas de Buenos Aires. Se basa en datos agregados relevados con un cuestionario aplicado a una muestra representativa de residentes de estos territorios. Se presenta primero una discusión sobre el concepto de religiosidad popular del que surge la aproximación al de prácticas religiosas que guía el análisis. Presentamos luego la incidencia y característica de dieciocho prácticas, comparando, donde es posible, con datos del Atlas de las creencias religiosas coordinado por Mallimaci (2013). Ahondamos con mayor profundidad en algunas de ellas: la de efectuar una promesa y la de tener altares en espacios domésticos; exploramos asimismo el peso de los medios de comunicación e internet como espacios que sostienen algunas prácticas y su incidencia en la ruptura con la identidad territorial de estos pobladores. Finalizamos analizando la autopercepción sobre el grado de práctica y su cambio a lo largo del tiempo, concluyendo que esta pareciera mantenerse estable y conformándose como una dimensión que acompaña «naturalmente» sus vidas. Los interrogantes del trabajo son: ¿cuáles son y qué características tienen las prácticas religiosas? ¿Qué expresan? ¿Qué vinculación tienen con los marcos institucionales religiosos? ¿Cómo se vinculan con los territorios en los que habitan? ¿Cuál es la vinculación entre prácticas y vivencias religiosas?

Palabras clave: prácticas religiosas, religiosidad popular, villas de emergencia de Buenos Aires.

\section{Diverse religious practices in Buenos Aires slums}

\begin{abstract}
The article describes and analyses the diversity of religious practices of Buenos Aires slums inhabitants. The analysis is based on aggregate data obtained through a questionnaire applied to a representative sample of residents. First, we present a discussion on the concept of popular religiosity that sustains our understanding of religious practices. We then analyze the incidence and characteristics of 18 practices, comparing them, when possible, with data from the Atlas of religious diversity coordinated by Mallimaci (2013). We delve into more depth on some of them: making a promise to a devoted figure, and having a domestic altar. We also explore the weight of the mass media and internet as spaces that sustain some practices. We end the study analyzing self-perception on the degree of religious practice, and its change over time; concluding that it tends to be stable; a dimension that is "naturally" part of their lives. The guiding questions of this article are: What are the characteristics of religious practices? What do they express? How do they relate to institutional religious settings? How do they relate to the territories inhabited? How do religious practices and religious experience relate?
\end{abstract}

Keywords: religious practices, popular religiosity, slums. 


\section{INTRODUCCIÓN}

Este trabajo se sumerge en las prácticas religiosas de habitantes de villas de emergencia de la Ciudad Autónoma de Buenos Aires $(\mathrm{CABA})^{1}$. Estos territorios de la ciudad conforman un espacio-tiempo de singulares características por la homogeneidad en las condiciones de vida de sus habitantes y su gran diversidad sociocultural, que se expresa, entre otros, en ricas y variadas manifestaciones religiosas. Marginalidad urbana, vulnerabilidad social, búsquedas de transformación, expresiones de esperanza y de fe, son todas dimensiones que expresan la vida de estos pobladores y dan forma a variadas manifestaciones de la religiosidad popular.

Durante 2014, en el marco del programa de investigación Condiciones de vida y religión radicado en la Facultad de Ciencias Sociales de la Universidad Católica Argentina efectuamos un estudio focalizado en las villas de la CABA que buscó indagar expresiones de fe de sus habitantes. Lo hicimos a través de un estudio enmarcado en una metodología cuantitativa. A una muestra representativa de cuatrocientas personas mayores de 17 años de las villas esparcidas a lo largo de la ciudad ${ }^{2}$, se les solicitó que contestaran un cuestionario cuyos principales ítems buscaban relevar creencias, devociones, prácticas y adscripciones religiosas de sus residentes. Este artículo se basa en algunos de los resultados del estudio; el objetivo es describir, analizar, y discutir específicamente las prácticas religiosas de los sectores más marginados de la $\mathrm{CABA}^{3}$. Presentamos primero una breve discusión sobre el concepto de religiosidad popular y nuestra aproximación al de prácticas religiosas, y luego, la incidencia y característica de diversas prácticas. Ahondamos seguidamente en el peso de los medios de comunicación como espacios que sostienen algunas prácticas y analizamos la autopercepción sobre la práctica que tienen los habitantes. Concluimos con reflexiones finales. Los interrogantes que guían el trabajo son: ¿cuáles son y qué características tienen las prácticas religiosas? ¿Qué expresan? ¿Qué

\footnotetext{
1 Según el Censo Nacional de Población de 2010, residen en las villas unas 163587 personas, lo que representa el 5,7\% de la población total de la CABA en ese año. Las villas están fuertemente concentradas en el sur de la ciudad. Las tres más grandes en superficie y en población son la villa 21-24 ubicada en Barracas; la villa 1-11-14 en el Bajo Flores, y la 31-31bis ubicada en Retiro.

2 Se seleccionaron los siguientes aglomerados de asentamientos precarios: del barrio Soldati (Villa 3-Fátima, Piletones y R. Carrillo); 2. La villa 1-11-14 del Bajo Flores; 3. Las villas Cildáńez e INTA del barrio de Lugano; 4. La villa 21-24 de Barracas, y 5. Las villas 31 y 31 bis de Retiro. Estos cinco aglomerados concentran al 85\% de la población que vive en las diecisiete villas y asentamientos de CABA. 3 Los resultados de todo el relevamiento y del trabajo efectuado están en Suárez, Ana Lourdes -dir (2015). A lo largo de todas las etapas de investigación participaron, además de las autoras de este artículo: Juan Martín López Fidanza, Javier Barra, Luz Lecour, Cecilia Galera y Agustín Grizzuti. Somos todos miembros del Programa Condiciones de Vida y Religión de la Facultad de Ciencias Sociales de la Pontificia Universidad Católica Argentina. El Programa es un espacio de investigación, formación e intercambio, desde el que realizamos diversas actividades académicas.
} 
vinculación tienen con los marcos institucionales religiosos? ¿Cómo se vinculan con los territorios en los que habitan? ¿Cómo se vinculan prácticas y vivencias religiosas?

\section{RELIGIOSIDAD POPULAR Y PRÁCTICAS RELIGIOSAS}

Las expresiones de «fe» en los sectores populares son diversas, variadas y se manifiestan en múltiples formas, evidenciando que «lo» religioso —o más bien aquello que remite a lo sagrado- acompaña la vida de las personas y es parte de su matriz de significaciones, prácticas y ritualidades (Suárez, 2016). El concepto de religiosidad popular, controvertido y discutido en la actualidad ${ }^{4}$, es útil a nuestro entender, ya que permite adentrarse en las expresiones culturalmente mediadas de la fe. Proponemos un acercamiento al concepto desde el entrecruce de dos enfoques. Uno que refiere al tipo y grado de vínculo con lo religioso en cuanto espacio/s socialmente instituido/s (creencias, dogmas, prácticas y rituales con anclaje institucional). El segundo resalta aspectos culturales y simbólicos que se evidencian en estructuraciones de sentido y en prácticas religiosas en estos sectores.

El primer enfoque está bien sintetizado en la metáfora de Renée de la Torre, cuando propone comprender la religiosidad popular como un "Entre-medio», entre la religión institucional y la espiritualidad individualizada y vivida por fuera de las instituciones. Se destaca así que muchos creyentes toman elementos del culto propuesto por las instituciones religiosas preponderantes, reapropiándolos y resignificándolos, y asimismo de otras creencias no oficiales conformadas por la tradición oral que es vehiculizadora de muchos de sus elementos parainstitucionales. La religiosidad popular no es necesariamente paralela sino transversal a la institución y se desarrolla en sus propios intersticios antes que por fuera de ella (De la Torre, 2012, p. 511). Estas expresiones religiosas se conforman como «un soporte fundamental para la elaboración de respuestas ante los múltiples interrogantes de la existencia” (Ameigeiras, 2008, p. 25). Antes que una correspondencia a pertenencias institucionales, se trata de la dinámica existencial y vital de apropiación y resignificación de legados y valoraciones, a partir de un particular modo de relación con lo sagrado.

El segundo enfoque queda bien sintetizado con la metáfora "Otra lógica». Con estas palabras Cristian Parker (1993) caracterizó un trabajo que tuvo fuerte repercusión en los estudios sobre religiosidad popular. Su contenido refiere a: «la alternativa a la racionalidad ilustrada y al tipo de fe racionalizada que es su subproducto" (Parker, 1993, p. 192). Se entroncaría en las perspectivas culturalistas que intentan caracterizar un estrato cultural propio de Latinoamérica que sería fruto

\footnotetext{
4 Ver Martin (2007). La autora analiza los varios estudios efectuados en Argentina sobre religiosidad popular y señala las dificultades inherentes al concepto en su definición conceptual y operacional.
} 
de la sedimentación de los procesos sociohistóricos por los que atravesó nuestro subcontinente.

El concepto destaca la positividad creadora de los sectores populares. Complementa esta perspectiva Semán (2001) proponiendo que las motivaciones humanas en sectores populares se anclan en dimensiones cosmológicas, holísticas y relacionales ${ }^{5}$, argumentando que estas son expresiones de la forma que toma el vínculo con lo sagrado. Las ritualidades, prácticas y devociones expresan este vínculo y a su vez canalizan formas de ser, de estar y de transformar contextos, sean estos sociales, eclesiales, políticos, etc. Dado que la cultura popular es algo dinámico, se moldea, entre otras dimensiones, por las diversas formas de entender cómo lo sagrado, lo trascendente, interviene en la historia.

La religiosidad popular, entendida en el cruce de las dos aproximaciones presentadas se torna un espacio privilegiado para captar formas de ser, de estar y de expresar la vinculación con lo sagrado. Permite, por tanto, abordar dimensiones que remiten a una categoría transversal a "lo religioso»: la espiritualidad. Esta categoría está sustentada en experiencias "corporales» y simbólicas de lo trascendente y lo sagrado. «Lo religioso, lo sagrado y la espiritualidad se entrecruzan constituyendo un espacio que requiere una mirada conjunta para captar no solo su interrelación, sino su especificidad» (Suárez, 2016, p. 56). Este espacio, en los sectores populares — debido a sus «despojadas e injustas» situaciones de vida—, adquiere connotaciones que remiten a búsquedas de reconocimiento social, de identidad y de transformación. Así, desde esta perspectiva, la religiosidad de los sectores populares expresa por un lado la diversidad de sentidos e identidades socioculturales de aquel colectivo, rescatando a su vez su "agencia»", sus anhelos y esperanzas (Suárez, 2016).

La forma en que las personas se vinculan con lo sagrado; la manera en que mantienen activas sus creencias, los rituales por los que sus devociones y vivencias religiosas se conservan, se alimentan y se significan, son expresiones de nuestra aproximación a las "prácticas religiosas». Así definidas, estas incluyen un espectro grande de posibilidades y de clasificaciones; comprenden la asistencia al culto — aspecto privilegiado en los estudios académicos por asumirse como el más relevante- y muchas otras más. Estas prácticas pueden categorizarse según sean de tipo más individual o comunitario;

\footnotetext{
5 La experiencia cosmológica que impregna la cultura de los sectores populares, según Semán, busca visibilizar que lo sagrado es un nivel más de la realidad y, por lo tanto, tienden a diluirse las distinciones entre lo trascendente e inmanente, entre lo natural y lo sobrenatural. Lo divino actúa siempre y en todos los planos. La experiencia holística lleva a concebir un vínculo intrínseco y una continuidad profunda entre lo físico, lo moral y lo espiritual; y a actuar por tanto desde la aproximación de totalidad del hombre (Semán, 2001, pp. 45-74). La dimensión relacional sustenta una concepción comunitaria cimentada en la solidaridad.

6 Agencia, tal como lo concibe Amartya Sen (2000) en tanto habilidad de luchar por objetivos que uno valora y tiene razón de valorar. Una persona con agencia es alguien que genera transformaciones.
} 
según se realicen en espacios privados o públicos; según el grado en que responden a rituales institucionalmente establecidos, o según el tipo y grado de compromiso religioso que expresan (Suárez, 2015). Las prácticas religiosas, en síntesis, son aspectos que ayudan a comprender cómo las personas viven y expresan su fe.

\section{INDAGANDO EN LAS PRÁCTICAS RELIGIOSAS...}

El cuestionario diseñado en nuestro estudio relevó un grupo de dieciocho prácticas religiosas. A todas las personas, incluyendo a las que dijeron no creer en Dios o ser personas no religiosas, se les pidió que indicaran, para cada práctica, si la habían o no realizado en el último año.

El cuadro 1 muestra el listado de diecisiete prácticas ordenado por el porcentaje de respuestas afirmativas. El primer lugar del ranking, con porcentajes rondando el $87 \%$, lo ocupan dos prácticas: (i) rezar u orar en casa, y (ii) asistir al templo o iglesia para la ceremonia de su culto. Se trata de actividades muy distintas. La primera, rezar en casa, es una actividad efectuada desde un ámbito doméstico, lugar desde el que se toma la iniciativa de entablar un vínculo «personal» con lo sagrado. Si bien nada puede inferirse por la pregunta acerca de la forma en que cada persona lo hace (si recurre a oraciones o fórmulas establecidas, si lo hace solo o acompañado), ni de la frecuencia e intensidad de su oración, ni la intención del rezo (agradecer, pedir, etc.). El porcentaje de respuesta tan alto a esta pregunta puede leerse como revelador de la existencia de un espacio "propio» para el vínculo con la trascendencia. La segunda práctica, contrariamente a la primera, se realiza en un ámbito institucional mediante la participación en ceremonias con una ritualidad establecida. La fuerte incidencia, en síntesis, de prácticas religiosas con connotaciones tan distintas puede leerse como indicador de que en la orquestación del vínculo con lo sagrado lo institucional y lo personal se complementan.

Las prácticas con una incidencia media, según nuestro ranking, son variadas: leer libros y folletos religiosos (58,7\%), asistir a fiestas religiosas $(50,9 \%)$, recibir la imagen de la virgen en la casa (47\%) y leer la Biblia (45,3\%). Las dos primeras refieren a prácticas que implican lectura de algún material religioso. Llama la atención el alto porcentaje que manifiesta haber leído la Biblia en algún momento del año: posiblemente esté indicando un contacto personal o comunitario del que puede inferirse una adherencia y valoración de esta fuente primaria de la fe cristiana y un contacto con independencia de mediaciones. El alto porcentaje que recibió la imagen de la virgen en su casa muestra el tipo de pastoral desarrollada en estos espacios desde la Iglesia católica, que es justamente que la imagen de la virgen pase por diversos hogares en los que permanece algunos días para dar soporte a prácticas domésticas de oración. 
Las prácticas con incidencia media-baja comprenden a aquellas que entre un tercio y un cuarto de la población manifiesta haber realizado al menos una vez en el año. Son prácticas muy variadas, que incluyen algunas que se realizan en espacios públicos como concurrir a una peregrinación o procesión, rezar en una ermita en la calle y concurrir a santuarios; otras que se realizan por lo general dentro de los templos o iglesias: comulgar o participar de la santa cena, y confesarse; otras cuyo lugar de realización puede ser muy diverso, como realizar una ofrenda y asistir a novenas. Esta última práctica se materializa en general con el rezo del rosario, oración típica de la Iglesia católica. Las novenas se realizan en general en preparación a una festividad; por ejemplo, la fiesta del santo/a patrono/a del barrio o capilla. Queda finalmente la práctica de participar en algún ritual por un difunto, cuya forma de realización es muy diversa: comporta el ritual del velorio apenas fallece una persona, y asimismo una serie de prácticas conmemorativas de los difuntos que mantienen viva la memoria de los seres queridos.

Finalmente, las prácticas con menor incidencia (aquellas que varían entre el 17\% y $7 \%$ ) son cuatro. Dos de ellas implican un alto compromiso, sea para "salir» a testimoniar públicamente la fe — tal es el caso de la práctica de misionar o predicar-o la decisión de darse un espacio para una formación e introspección intensiva - como en el caso de la práctica de asistir a retiros o encuentros espirituales. Las otras dos prácticas - la de tener un encuentro carismático con el Espíritu Santo y la de asistir a un culto de prosperidad o siembra - tienden a circunscribirse en general al espacio evangélico, de ahí posiblemente su menor incidencia. El cuestionario dejó una pregunta abierta, donde las personas podían detallar alguna otra práctica religiosa efectuada. El ítem obtuvo muy pocas respuestas y en general estas podían encuadrarse dentro de las dieciocho anteriores. Solo una práctica dentro de este espacio para "otras» vale destacar: la de haber orado por endemoniados y haber participado en manifestaciones de endemoniados.

Los párrafos anteriores denotan, en síntesis, que el espectro de prácticas religiosas es amplio; sus contenidos, espacios y ritualidad son, asimismo, muy variados. La incidencia de su realización pareciera también más alta con relación a otros territorios. Para algunas de las prácticas podemos comparar con los resultados nacionales y del AMBA aportados por el Atlas de las creencias religiosas en la Argentina dirigido por Mallimaci (2013). Rezar en casa, leer la Biblia y concurrir a una peregrinación o procesión en las villas de CABA tienen diferencias porcentuales de 15 puntos, aproximadamente, respecto del AMBA (cuadro 1). Las diferencias porcentuales de las tres prácticas mencionadas y las de misionar, asistir a novenas y asistir a retiros con los porcentajes nacionales son menores: rondan entre 5 y 10 puntos, salvo en leer la Biblia, donde los porcentajes son muy similares (cuadro 1). 


\section{Cuadro 1. Respuesta afirmativa por localización territorial}

(Porcentaje)

\begin{tabular}{|c|c|c|c|c|}
\hline \multirow{2}{*}{ Practicó en el último año } & \multicolumn{2}{|c|}{ Villas de CABA } & \multirow{2}{*}{ AMBA } & \multirow{2}{*}{$\begin{array}{l}\text { Total } \\
\text { país }\end{array}$} \\
\hline & Porcentaje & Ranking & & \\
\hline $\begin{array}{l}\text { Asistir a templo o iglesia para ceremonia } \\
\text { de su culto }\end{array}$ & 87,2 & 1 & & $\begin{array}{c}73,2 \\
(*)\end{array}$ \\
\hline Rezar u orar en su casa & 87 & 2 & 70,6 & 78,3 \\
\hline Leer libros o folletos religiosos & 58,7 & 3 & & 39,4 \\
\hline Asistir a fiesta religiosa & 50,9 & 4 & & \\
\hline Recibir la imagen de la virgen en su casa & 47 & 5 & & \\
\hline Leer la Biblia & 45,3 & 6 & 33,1 & 42,8 \\
\hline Comulgar o participar en la santa cena & 38 & 7 & & \\
\hline Rezar en una ermita en la calle & 33,8 & 8 & & \\
\hline Concurrir a una peregrinación o procesión & 31,5 & 9 & 13,5 & 26,3 \\
\hline Realizar una ofrenda & 30,6 & 10 & & \\
\hline Confesarse & 30,2 & 11 & & \\
\hline Concurrir a santuarios & 29,5 & 12 & & 31,0 \\
\hline Participar de algún ritual por difunto & 28,5 & 13 & & \\
\hline Asistir a novenas & 25,6 & 14 & & \\
\hline Misionar o predicar & 17,4 & 15 & & 9 \\
\hline $\begin{array}{l}\text { Tener un encuentro carismático con el } \\
\text { Espíritu Santo }\end{array}$ & 15,3 & 16 & & \\
\hline Asistir a retiros o encuentros espirituales & 15 & 17 & & 7,8 \\
\hline
\end{tabular}

Fuente. Procesamientos propios a partir de la Encuesta sobre la presencia religiosa en asentamientos 2014-UCA, publicado en Suárez, 2015, p. 92.

Para AMBA y total país se tomaron datos publicados en Mallimaci 2013 a partir de la Encuesta sobre Religión y Estructura Social - 2008.

$\left(^{*}\right)$ El dato es estimativo. La pregunta sobre frecuencia de asistencia al culto en la encuesta de la UCA y la CEIL difirió en sus categorías. La de la UCA incluía una referida a la asistencia al menos una vez al año; la del CEIL no. Construimos el dato del CEIL restando del total a aquellos que afirmaron nunca asistir a sus ceremonias.

Para algunas de las prácticas, nuestro cuestionario dejó un ítem abierto para que fuera nombrado el lugar de realización. Los encuestados identificaron los lugares de culto, santuarios, ermitas, así como las peregrinaciones, procesiones, etc. en las que participaron. Localizamos cada una de las referencias dadas y quedó muy en relieve 
que las prácticas religiosas de la población son efectuadas en su gran mayoría dentro de las fronteras de los barrios donde viven?

Puede concluirse que la población en villas de CABA expresa su fe y la mantiene viva a través de prácticas religiosas en porcentajes algo superiores al conjunto de la población del AMBA y del total del territorio del país. ¿En qué medida la autoafiliación religiosa introduce diferencias? Para responder la pregunta veamos primero las afiliaciones religiosas. Las pertenencias religiosas en las villas, ordenadas según su grado de incidencia, son las siguientes (Suárez, 2015): católica (76,4\%), evangélica $(12,3 \%)$, ninguna $(7,5 \%)$, testigos de Jehová $(2 \%)$, adventista $(1,3)$, y, compartiendo el mismo grado de incidencia: Umbanda e Iglesia de los Santos de los Últimos Días (mormones) (0,3\%). Cabe destacar la ausencia de afiliaciones religiosas que, aunque en forma muy minoritaria, están presentes en CABA, como la judía, la musulmana y la budista u otras de origen oriental. El espacio religioso de referencia de la población en villas, por tanto, es de clara preeminencia cristiana: poco más de nueve de cada diez residentes en las villas se inscribe en alguna denominación cristiana, de las cuales la católica es la mayoritaria. Esta autoadscripción, vale la pena remarcar, nada dice del grado de adhesión, de práctica, ni de compromiso religioso; solo dice que en alguna medida la estructuración simbólica y de sentidos de la población se vincula con una matriz de configuración religiosa en la que la cristiana es preeminente.

¿En qué medida y cómo la afiliación religiosa afecta el ranking de las dieciocho prácticas relevadas?8. Las dos primeras prácticas religiosas siguen liderando el ranking en todas las categorías. Católicos y evangélicos en porcentajes que superan el $85 \%$ manifiestan que en el último ańo han tanto rezado en sus casas como asistido al templo para la ceremonia de su culto9. Lo destacable es que, entre aquellos sin

\footnotetext{
7 Centrándonos específicamente en los lugares de culto, se constata que aquellos ubicados en territorios de clase media o alta, contrariamente a aquellos en espacios marginales de la ciudad, además de recibir a residentes de los barrios donde están emplazados, reciben un flujo de personas que se trasladan desde otros barrios. O sea los creyentes con mayores recursos económicos «eligen» el lugar de culto al que quieren asistir y se desplazan a él aun si el traslado implica recorrer distancias dentro de la ciudad. Un interesante trabajo en esta línea es el coordinado por Brenda Carranza (2015). El estudio compara dos parroquias católicas de la ciudad de Campinas en San Pablo, una de un barrio céntrico de la ciudad, y la otra de un barrio periférico. Una de las principales conclusiones del trabajo es la que acabamos de mencionar: la afluencia de personas de distintos barrios en la primera parroquia es muy superior a la de la segunda.

8 El análisis efectuado para responder a esta pregunta se focalizó en los autoafiliados católicos, los evangélicos y aquellos sin religión. Se excluyó a los paracristianos (mormones, testigos de Jehová y adventistas), por su número de casos, lo que podría afectar la significación de los resultados.

9 Entre personas de afiliación paracristiana — no incluidos en el cuadro- estas dos prácticas tienen un muy alto grado de incidencia. Según nuestros datos, todos los encuestados de afiliación adventista, mormona o testigo de Jehová afirmaron haber rezado en su casa y haber asistido a las ceremonias de su culto.
} 
afiliación religiosa, ambas prácticas religiosas, junto con la de leer libros o folletos religiosos, ocupan también los primeros lugares en porcentajes que oscilan entre el $42 \%$ y el $50 \%$. Dicho en otras palabras, alrededor de la mitad de las personas sin afiliación religiosa afirma haber rezado, asistido a un culto religioso o leído literatura religiosa ${ }^{10}$.

En las prácticas religiosas de incidencia media, media-baja y baja, sí se observan modificaciones en el ranking según afiliación religiosa. Para ordenar el análisis, las comentamos por afiliación. Comenzamos por aquellos sin afiliación alguna. La diferencia porcentual entre las tres primeras prácticas religiosas recién comentadas y las restantes es alta, lo que indica que, como es esperable, las personas sin afiliación religiosa, se involucran muy poco en actividades de índole religiosa. Tres prácticas religiosas, sin embargo, merecen destacarse, ya que su incidencia es relativamente alta para este grupo de personas. La participación en algún ritual por un difunto involucró a casi un cuarto de este grupo; asistir a una fiesta religiosa y recibir a la imagen de la virgen en sus casas al 16,7\% y al 17,2\% respectivamente. Si bien posiblemente pueda estar influyendo en estos porcentajes el aspecto social de estas prácticas, el dato merecería ahondarse con análisis que se adentren en el significado que para estas personas tiene el mundo religioso.

Entre los evangélicos, dos prácticas religiosas suben considerablemente su valor: leer la Biblia $(87,5 \%)$ y leer libros o folletos religiosos $(71,4 \%)$. Se destacan, así, actividades religiosas que responden al acento puesto en la tradición evangélica. Asimismo, todas las prácticas religiosas que en el ranking global se ubican entre las de incidencia baja (con porcentajes inferiores al 20\%), entre los evangélicos suben a las de media baja (con porcentajes de $40 \%$ a $22 \%$ ). Nos referimos a: misionar o predicar, tener un encuentro carismático con el Espíritu Santo, asistir a retiros espirituales y participar de un culto de prosperidad o siembra. A su vez, seis de las prácticas religiosas que en el ranking global tienen incidencia media-baja, entre los evangélicos, descienden a las rankeadas como bajas. Se trata en su mayoría de actividades religiosas de tradición católica que involucran devociones marianas o a los santos (asistir a novenas, concurrir a santuarios, rezar en una ermita). Claro que otra lectura de estos últimos datos destaca que, pese a los bajos valores que alcanzan ciertas prácticas religiosas típicas de la tradición católica tienen alguna incidencia entre los evangélicos, lo que evidencia la porosidad entre adscripciones e indica que las fronteras entre las adscripciones religiosas son flexibles.

10 Las encuestas que relevan creencias y prácticas religiosas no suelen efectuar preguntas referidas a prácticas religiosas a aquellos que se autodefinen como sin religión. Se suele asumir que se trata de ateos o de agnósticos y que, por lo tanto, no tienen práctica religiosa alguna. Nuestros datos muestran lo atinado que ha sido no efectuar el «filtro». Suscita, asimismo, el interés por indagar la motivación y el significado vinculado con cada práctica. 
Entre los católicos, el ranking de prácticas religiosas es muy similar al global: caben para ellos, por tanto, los comentarios generales ya efectuados. Sin embargo, aun manteniéndose cerca en el ranking, algunas prácticas suben significativamente su incidencia. Tal el caso de rezar en una ermita en la calle y concurrir a una peregrinación. Aquellas que mayor peso pierden son las prácticas religiosas típicas de la tradición evangélica. Cabe aquí el mismo comentario efectuado en el párrafo de arriba referente a los evangélicos. La presencia de estas prácticas entre los católicos, aun si su incidencia baja, es un indicador de la porosidad entre adscripciones religiosas.

\section{Promesas y devociones. Presencia de altares en las casas}

El listado de dieciocho prácticas analizadas en la primera sección no incluye dos que fueron relevadas en nuestro cuestionario: hacer una promesa y tener un altar en la casa. Ambas están estrechamente vinculadas con devociones. Una promesa es un voto u ofrecimiento religioso que se hace junto con una petición a Dios, Jesús, la virgen María o un santo. La práctica de esta costumbre, muy arraigada en la tradición católica, normalmente consiste en pedir favores a un santo a cambio de lo cual se promete un sacrificio personal. Se entiende que, si el santo accede al pedido, el creyente debe cumplir con la promesa. La mayoría de las promesas son personales y su celebración es privada. Una persona podría, por ejemplo, hacer una peregrinación o rezar una novena o serie de rosarios. A veces las personas hacen sacrificios muy grandes, como desplazarse de rodillas en un santuario hasta llegar a "tocar» al santo o virgen al que se le hizo la promesa. La segunda, tener un altar en su casa, en realidad más que una práctica religiosa, es un espacio sustentador de prácticas. Algunas de las listadas en la sección anterior pueden tener como entorno un altar doméstico, como por ejemplo orar, rezar novenas o leer la Biblia.

Cuatro de cada diez personas en las villas de CABA manifestaron haber hecho una promesa religiosa, y casi la mitad manifestó haberla hecho a la virgen, santo o cristo del cual se es devoto. Para comprender mejor este aspecto veamos primero las devociones de la población. El 82\% manifestó ser devoto de un santo, virgen o cristo. La pregunta en el cuestionario era abierta, por lo que pudieron expresar con comodidad sus devociones. La mitad de los que dijeron tener devociones, nombraron a la virgen, y en muchos casos lo hicieron bajo alguna advocación. Las dos vírgenes que más se mencionan son las de Caacupé (típica de la cultura paraguaya), y la de Luján (patrona de la Argentina) (ver imagen 1) ${ }^{11}$. Entre los santos y santas, quienes reciben mayores menciones son San Cayetano, el Gauchito Gil y San Expedito (ver

11 En tercer lugar aparecen menciones a las vírgenes de Guadalupe (patrona de América) y la de Fátima, seguidas de cerca por las de Copacabana y Urkupińa (de la cultura boliviana). Otras vírgenes que se mencionan son las del Carmen, la de la Medalla Milagrosa, la del valle de Catamarca, la de María Auxiliadora, la de la Puerta (venerada en Perú), la del Socavón (venerada en Oruro, Bolivia), la 
imagen 1$)^{12}$. La mención a Jesucristo tiene también una fuerte incidencia: un cuarto de quienes expresaron una devoción lo mencionan; se lo nombra bajo el nombre de Jesús, de Cristo, del niño Jesús, del Señor de los Milagros y del Sagrado Corazón.

Imagen 1. Virgen y santo del cual se es devoto según cantidad de menciones
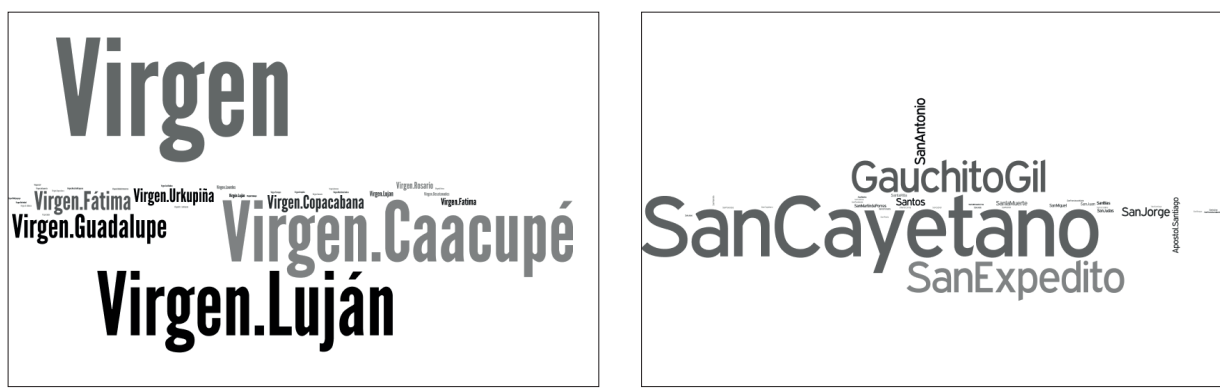

Fuente. Encuesta sobre la presencia religiosa en asentamientos. 2014- UCA. Publicado en Suárez 2015, p. 97.

Cada una de estas devociones se asocia a contextos, tradiciones y culturas. Excede los objetivos de este artículo ahondar en estos aspectos. Cabe solo mencionar tres cuestiones: (i) la relevancia que tienen devociones típicas de países limítrofes con Argentina, especialmente en el caso de las vírgenes; (ii) la presencia de devociones populares no oficialmente reconocidas por la Iglesia, especialmente en el caso de algunos santos, coexistiendo con devociones «oficiales», y (iii) la división entre vírgenes y santos por género. Las primeras son, obviamente, del género femenino. Las devociones a los santos y santas son principalmente masculinas. La devoción a santas (mujeres) es muy baja. Cabe destacar finalmente, considerando aspectos sociodemográficos, que ser devoto es más fuerte entre las personas de mayor edad y entre los nacidos en países limítrofes. El sexo, en cambio, no introduce mayores diferencias.

Volviendo a la práctica de las promesas, la mitad de los devotos, como ya hemos mencionado, manifestó haber efectuado una promesa a quien es objeto de su devoción. Estrecharon así un vínculo que comporta confianza, entrega, obligación. Los aspectos sociodemográficos no introducen diferencias relevantes en este aspecto. Cabe solo mencionar que la práctica es levemente mayor entre los nacidos en países limítrofes (cuadro 2).

de Huasca (México), la del Rosario de San Nicolás, la de Medjugorje, la de Lourdes, Nuestra Señora de Pompeya, la de Itatí y la Virgen Desatanudos.

12 Se mencionan varios otros santos, pero cada uno con baja incidencia. La nómina se completa con san Francisco, san Judas Tadeo, san José, san Jorge, san Gabriel, san Antonio, san Blas, san Miguel, san Valentín, san Pedro, san Roque, san Benito, san Ramón Neonato, san Pantaleón, san Juan Bautista, san Santiago, santa Teresita, santa Rosa de Lima, santa Rita. Se mencionan asimismo a la Difunta Correa y a san La Muerte. 


\section{Cuadro 2. Respuesta afirmativa por adscripción religiosa}

(Porcentaje)

\begin{tabular}{|c|c|c|c|c|}
\hline \multirow{2}{*}{ Practicó en el último año... } & \multicolumn{3}{|c|}{ Adscripción religiosa $(*)$} & \multirow{2}{*}{ Total } \\
\hline & Católica & Evangélica & Ninguna & \\
\hline $\begin{array}{l}\text { Asistir a templo/iglesia para ceremonia } \\
\text { de su culto }\end{array}$ & 90,1 & 89,7 & 42,8 & 87,2 \\
\hline Rezar u orar en su casa & 88,8 & 98 & 46,7 & 87 \\
\hline Leer libros o folletos religiosos & 56 & 71,4 & 50 & 58,7 \\
\hline Asistir a fiesta religiosa & 57,6 & 36,7 & 16,7 & 50,9 \\
\hline Recibir la imagen de la virgen en su casa & 57,6 & 12,2 & 17,2 & 47 \\
\hline Leer la Biblia & 39,1 & 87,5 & 23,3 & 45,3 \\
\hline Comulgar o participar en la santa cena & 38,9 & 47,9 & 3,6 & 38 \\
\hline Rezar en una ermita en la calle & 41,7 & 6,5 & 10,3 & 33,8 \\
\hline Concurrir a una peregrinación o procesión & 38,9 & 8,2 & 10 & 31,5 \\
\hline Realizar una ofrenda & 29,2 & 52,1 & 6,7 & 30,6 \\
\hline Confesarse & 34,7 & 16,3 & 6,9 & 30,2 \\
\hline Concurrir a santuarios & 36,9 & 4,1 & 10 & 29,5 \\
\hline Participar de algún ritual por difunto & 33,4 & 6,3 & 23,3 & 28,5 \\
\hline Asistir a novenas & 31,8 & 4,3 & 10,3 & 25,6 \\
\hline Misionar o predicar & 14,6 & 35,4 & 0 & 17,4 \\
\hline $\begin{array}{l}\text { Tener un encuentro carismático con el } \\
\text { Espíritu Santo }\end{array}$ & 13,4 & 39,6 & 0 & 15,3 \\
\hline Asistir a retiros o encuentros espirituales & 13,3 & 30,6 & 3,3 & 15 \\
\hline Culto de prosperidad o siembra & 5,2 & 22 & 3,7 & 7,6 \\
\hline
\end{tabular}

$\left.{ }^{*}\right)$ : No incluye a los paracristianos (mormones, testigos de Jehová y adventistas).

Fuente. Procesamientos propios a partir de la encuesta sobre la presencia religiosa en asentamientos 2014 - UCA. Publicado en Suárez, 2015, p. 158.

Tener un altar doméstico es una práctica de poco más de la mitad de la población en villas (cuadro 2). Como sugerimos ya, más que una práctica religiosa, es una instancia habilitadora de diversas expresiones de fe que pueden efectuarse fuera de la institución religiosa. Las imágenes que componen estos altares son variadas y tienden a coincidir con las devociones personales y familiares. Las imágenes más frecuentes son de la virgen en sus diversas advocaciones; en tres cuartas partes de 
quienes tienen un altar la imagen de la virgen está presente ${ }^{13}$. Junto a esta imagen suele haber imágenes de algún santo. En varios altares hay, asimismo, fotos de familiares difuntos, y en algunos, la foto del papa Francisco. ¿Cómo impacta la presencia de un altar en las prácticas religiosas de las personas? No lo podemos saber; no fue preguntado en el cuestionario. Es posible que su presencia en un «territorio» doméstico, desde la perspectiva de los miembros del hogar, articule su mundo, su espacio doméstico, con lo «sagrado». Su presencia puede ser concebida como expresiones de prácticas de sacralización (Martin, 2007) en el ámbito doméstico.

Cuadro 3. Devociones, promesas y presencia en el altar en la casa. Total y por aspectos sociodemográficos

\begin{tabular}{|c|c|c|c|c|c|c|c|c|c|}
\hline & \multirow[t]{2}{*}{ Total } & \multicolumn{2}{|c|}{ Sexo } & \multicolumn{3}{|c|}{ Grupo de edad } & \multicolumn{3}{|c|}{ Situación migratoria } \\
\hline & & $\begin{array}{c}\text { Varón } \\
\%\end{array}$ & $\begin{array}{l}\text { Mujer } \\
\%\end{array}$ & $\begin{array}{c}18-24 \\
\%\end{array}$ & $\begin{array}{c}25-44 \\
\%\end{array}$ & $\begin{array}{l}45 \text { y } \\
\text { más } \\
\%\end{array}$ & $\begin{array}{c}\text { Países } \\
\text { limítrofes } \\
\%\end{array}$ & $\begin{array}{c}\text { Argentina } \\
\text { no AMBA } \\
\%\end{array}$ & $\begin{array}{c}\text { AMBA } \\
\%\end{array}$ \\
\hline $\begin{array}{l}\text { Es devoto de algún } \\
\text { santo, virgen o Cristo* }\end{array}$ & 82,0 & 79,9 & 83,9 & 76,0 & 82,8 & 98,2 & 87,3 & 78,3 & 75,2 \\
\hline $\begin{array}{l}\text { Sí es devoto, menciona a } \\
\text { la virgen** }\end{array}$ & 52,1 & 48,3 & 55,4 & 53,3 & 46,8 & 61,0 & 54,6 & 57,4 & 45,9 \\
\hline $\begin{array}{l}\text { Le hizo una promesa al } \\
\text { santo o virgen de quien } \\
\text { es devoto o a algún } \\
\text { otro*** }\end{array}$ & 48,7 & 50,3 & 47,2 & 49,0 & 46,5 & 52,4 & 52,4 & 42,1 & 45,7 \\
\hline \multirow{2}{*}{$\begin{array}{l}\text { Tiene un altar en su casa } \\
\text { por pequeńo que sea**** }\end{array}$} & 55,0 & 54,5 & 55,5 & 57,0 & 52,7 & 57,0 & 58,8 & 49,3 & 51,3 \\
\hline & 100.0 & 100,0 & 100,0 & 100,0 & 100,0 & 100,0 & 100,0 & 100,0 & 100,0 \\
\hline
\end{tabular}

$\left({ }^{*}\right)$ : Base 400 casos. $\left({ }^{* *}\right)$ : Base 328 casos. $\left({ }^{* *}\right)$ : Base 339 casos. $\left({ }^{* * *}\right)$ : Base 217 casos.

Fuente: Procesamientos propios a partir de la Encuenta sobre la presencia religiosa en asentamientos 2014 - UCA.

\section{Prácticas Religiosas digitales}

Desde hace varios años, las ciencias de la comunicación y la sociología de la religión vienen realizando estudios sobre la utilización de los medios y tecnologías de comunicación por diversos grupos religiosos. Brasil es el país con mayor producción en el campo que denominamos comunicación y religión. Sa Martino (2014) ha realizado una sistematización con las principales líneas de trabajo de este país, que, junto a nuestras propias investigaciones en lengua española, pueden ofrecer un panorama general de la región. No es casual que en Brasil, para 2014, la revista Religiäo \&

13 Si se toma a la población total con independencia de tener o no un altar en su casa, un $41,5 \%$ de los habitantes de villas de CABA tiene en su casa un altar con una imagen de la virgen. 
Sociedade publicara un dossier sobre Medios y Religión. Sa Martino (2014) marca el inicio del interés por los medios de comunicación y religión en la década de 1950, con el movimiento «radioevangelista» en Estados Unidos. Son personas relevantes de este momento el obispo católico Sheen y el pastor evangélico Graham, ambos de Estados Unidos. En esos años nace la televisión ${ }^{14}$. La investigación con mayor relevancia es la de Assmann (1986) sobre la iglesia electrónica en América Latina. También Martín-Barbero (1995), en su trabajo Secularización, desencanto y reencantamiento masmediático, ofrece una interesante perspectiva para pensar la relación entre modernidad, religiosidad y medios. Si bien su reflexión en esta obra se fundamenta en la revolución que aportó lo que llamamos «iglesia electrónica», parte de la idea de que los medios de comunicación son los referentes culturales desde los cuales las personas constituyen el sentido de su vida. Esta afirmación posee gran valor heurístico en la actualidad para la reflexión sobre los medios masivos en general, llegando a los consumos digitales. Otro tema de relevancia es abordado por Souza (2005) sobre los padres cantores de Brasil y más recientemente el de Carranza (2011) sobre catolicismo mediático que evidencian diferentes aspectos sobre la mediatización que se realiza del discurso religioso. También en el Perú, Pérez (2012) aborda el tema de las representaciones y mediatizaciones públicas de la religión, donde ofrece una interesante reflexión sobre medios, religión y cultura y sobre el fenómeno religioso en general. En Argentina sobre esta temática, desde otra perspectiva, está el libro coordinado por Algranti (2013), La industria del creer. Sociología de las mercancías religiosas. El enfoque de esta investigación pone el énfasis en la «mercantilización» del objeto religioso mediatizado, estudiando su consumo e implicancias en cuanto a la reproducción del sistema social.

Los antecedentes y las consideraciones de los autores relevados ayudan a reconocer que, si bien el territorio es de relevancia en el espacio estudiado (Suárez, Mitchell y Lépore, 2014), de igual modo la penetración mediática abre un campo de prácticas diversas que es necesario reconocer y profundizar. Los habitantes de las villas tienen acceso a los consumos culturales analógicos y digitales. Esto ha sido favorecido por el Estado con diversos programas de inclusión digital, si bien el servicio es de calidad inferior al que se ofrece en los barrios centrales de la ciudad.

Es interesante destacar que algunos estudios muestran que las prácticas culturales en general, y las religiosas en particular, que se realizan cara a cara, tienden a reproducirse en la virtualidad (ver Sbardelotto, 2014; Carranza, 2013, entre otros).

\footnotetext{
14 Para fines de la década de 1960, Muniz Souza (1969) presenta su investigación sobre el pentecostalismo en San Pablo y el rol central de sus publicaciones y programas de radio en sus actividades para fortalecer los lazos establecidos con los fieles, y las estrategias de proselitismo. Este trabajo puso de relieve el carácter institucional y económico que caracterizó muchas de las expresiones religiosas vinculadas con los movimientos pentecostales.
} 
Por ejemplo, la práctica de "hacer adoración a la eucaristía», que se realiza en un determinado momento en las iglesias católicas, arrodillados, hoy se puede «vivenciar» en cualquier momento del día en las numerosas capillas virtuales que ofrece el ciberespacio. Una parroquia de Mendoza, Argentina, siguiendo con el ejemplo, ofrece la posibilidad de realzar esta práctica virtualmente en caso que uno esté enfermo, etc. Cuando se accede al sitio, lo que se ve es transmitido desde un canal de televisión mexicano; es mucho más económico retransmitir lo que otros pueden generar a tener que producir algo propio ${ }^{15}$.

Lo que deseamos poner de relieve es que está emergiendo un nuevo modo de relacionarse con lo sagrado que integra diversas espiritualidades en forma sincrética, no solo en lo estrictamente religioso, sino en lo cultural. La encuesta que realizamos para el estudio que proveyó los datos de este artículo confirma la prospectiva expuesta. Al consultar sobre las prácticas religiosas (ver cuadro 1), un 58\% de las personas encuestadas contestó que lee folletos religiosos. La fuerte presencia de la Iglesia católica en este territorio favoreció la presencia de medios de comunicación comunitarios que acompañan su tarea pastoral, centrada en una espiritualidad que recupera en primera instancia las necesidades reales de las personas. En consecuencia, estos medios de comunicación, que poseen la misma impronta, son muy leídos. No se encuentran en este territorio medios de comunicación con producción local de otras iglesias cristianas. Nuestro estudio ofrece datos de interés sobre el consumo de medios religiosos:

[...] el 37,3\% respondió afirmativamente consumirlos ${ }^{16}$. Al desagregar este porcentual por las variables de sexo, no hay diferencias significativas. Tomando en cuenta las edades, encontramos porcentajes semejantes entre los jóvenes y adultos mayores. La franja intermedia de 25 a 44 años es mucho más baja (ver cuadro 4). Considerando la pertenencia religiosa, se evidencia una fuerte diferencia entre el consumo católico, por un lado y la mayor exposición evangélica y para-cristiana por el otro (Suárez, 2015, p. 112).

Si bien los porcentajes no son altos, investigaciones de Brasil (ver Neto, 2006), donde el fenómeno es más estudiado, parecen indicar que esta integración de lo mediático a las prácticas religiosas va en aumento y que este proceso busca, en definitiva, ir al encuentro del mercado religioso que está en búsqueda de otras formas de vivenciar lo religioso.

15 Adoración virtual parroquia de Mendoza: http://www.parroquiasanagustinmendoza.com/429801647

16 El Atlas de las creencias religiosas (Mallimaci, 2013) relevó la categoría «ver programas religiosos», que en el país tiene una incidencia de $31 \%$. El dato no es comparable al nuestro, ya que incluimos radio y periódicos. 
Cuadro 4. Consumo de medios religiosos por sexo, grupos de edad y pertenencia religiosa. Distribución porcentual

\begin{tabular}{|c|c|c|c|c|c|c|c|c|c|}
\hline \multirow{2}{*}{$\begin{array}{l}\text { Consume } \\
\text { medios... }\end{array}$} & \multicolumn{2}{|c|}{ Sexo } & \multicolumn{3}{|c|}{ Grupo de edad } & \multicolumn{4}{|c|}{ Pertenencia religiosa } \\
\hline & Varón & Mujer & $18-24$ & $25-44$ & $\begin{array}{l}45 \text { y } \\
\text { más }\end{array}$ & $\begin{array}{l}\text { Cató- } \\
\text { lica }\end{array}$ & $\begin{array}{l}\text { Evan- } \\
\text { gélica }\end{array}$ & $\begin{array}{l}\text { Para- } \\
\text { crist. }\end{array}$ & $\begin{array}{l}\text { Nin- } \\
\text { guna }\end{array}$ \\
\hline Sí & 37,6 & 39,8 & 43,8 & 34,4 & 40,9 & 37,4 & 46,9 & 42,8 & 36,7 \\
\hline No & 62,4 & 60,2 & 56,2 & 65,7 & 59,1 & 62,6 & 53,1 & 57,2 & 63,3 \\
\hline Total & 100 & 100 & 100 & 100 & 100 & 100 & 100 & 100 & 100 \\
\hline & (189) & $(211)$ & $(121)$ & $(186)$ & (93) & $(305)$ & (49) & (14) & $(30)$ \\
\hline
\end{tabular}

Fuente: Procesamientos propios a partir de la Encuesta sobre la Presencia Religiosa en Asentamientos 2014 - UCA. Publicado en Suárez, 2015, p. 113.

Las consideraciones realizadas alcanzan de igual modo a internet. Nuestro estudio arrojó los siguientes resultados:

[...] un $15,8 \%$ lo realiza (cuadro 5). Dentro de este porcentaje se observa una leve incidencia mayor en las mujeres. Si miramos las respuestas por edad, comprobamos que a menor edad hay mayor relacionamiento con lo religioso vía internet. Aún si los valores porcentuales de interacción con lo religioso vía internet no son muy altos, es interesante continuar observando esta tendencia, ya que en nuestra muestra aparece como de gran crecimiento en relación a las edades consultadas (Suárez, 2015, p. 112).

Los porcentajes son menores, pero todo indica que este tipo de prácticas va en crecimiento, con mayor intensidad en el mundo evangélico, más allá de lo provisorio de estos resultados, ya que aún no son datos suficientemente significativos.

Cuadro 5. En el último mes, ¿̨te relacionaste con algo religioso por internet...? Según sexo, grupo de edad y pertenencia religiosa (distribución porcentual) $\left({ }^{*}\right)$

\begin{tabular}{|c|c|c|c|c|c|c|c|c|c|}
\hline & \multicolumn{2}{|c|}{ Sexo } & \multicolumn{3}{|c|}{ Grupo de edad } & \multicolumn{4}{|c|}{ Pertenencia religiosa } \\
\hline & Varón & Mujer & $18-24$ & $25-44$ & $\begin{array}{l}45 \text { y } \\
\text { más }\end{array}$ & $\begin{array}{c}\text { Cató- } \\
\text { lica }\end{array}$ & $\begin{array}{l}\text { Evan- } \\
\text { gélica }\end{array}$ & $\begin{array}{l}\text { Para- } \\
\text { crist. }\end{array}$ & $\begin{array}{l}\text { Nin- } \\
\text { guna }\end{array}$ \\
\hline Sí & 14,8 & 17,8 & 29,1 & 12,9 & 6,7 & 12,9 & 27,7 & 42,9 & 21,4 \\
\hline No & 85,2 & 82,2 & 70,9 & 87,1 & 93,3 & 87,1 & 72,3 & 57,1 & 78,6 \\
\hline \multirow[t]{2}{*}{ Total } & 100 & 100 & 100 & 100 & 100 & 100 & 100 & 100 & 100 \\
\hline & $(183)$ & $(202)$ & $(117)$ & $(178)$ & $(90)$ & $(295)$ & $(47)$ & (14) & $(28)$ \\
\hline
\end{tabular}

(*): No se tomó en consideración el caso de un fiel umbanda por no contar con suficientes datos para procesar. Fuente. Procesamientos propios a partir de la encuesta sobre la presencia religiosa en asentamientos 2014 - UCA. Publicado en Suárez, 2015, p. 115. 
La experiencia religiosa se está reconfigurando a partir de la mediatización tecnológica-comunicativa. Esto no es una novedad: Marshall Mc Luhan fue uno de los primeros en plantear que las tecnologías implican transformaciones en las personas. Con especial énfasis en su obra La Galaxia Gutenberg, explora las consecuencias de la incorporación de la imprenta en la vida social desde nuestra forma de leer, que articula nuestra forma de pensar. Algunos teóricos, como Drescher (2011), afirman que la reforma protestante también fue impulsada por las posibilidades de democratización del conocimiento que abrió la imprenta de Gutenberg (ver Drescher, 2011). Es necesario continuar la reflexión sobre los cambios que se abren a partir de las nuevas tecnologías de comunicación emergentes y de los nuevos usos del lenguaje, y la apropiación que los grupos religiosos están realizando de ellas. ¿Cómo será el futuro? Quedan muchos interrogantes. ¿Cómo serán "permeadas» las prácticas de religiosidad popular por la emergente cultura digital? ¿Se incrementará la porosidad de los límites entre las diversas experiencias religiosas? ¿La mayor cercanía virtual entre experiencias religiosas lejanas físicamente transformará las estructuras tradicionales o pasaremos a una mayor privatización de lo religioso? Grandes desafíos para la investigación que requieren también un trabajo interdisciplinario que permita encontrar nuevas herramientas y estrategias para abordar las transformaciones en acto.

\section{AuTOPERCEPCIÓN DE LA PRÁCTICA Y DE SUS CAMBIOS EN EL TIEMPO}

El cuestionario de nuestro estudio incluyó dos preguntas que permitieron una aproximación a la autopercepción de la práctica religiosa. Su formulación fue: «¿Usted considera que su grado de práctica es... alto, medio o bajo?» y «En los últimos años, ¿su práctica religiosa... creció, disminuyó o se mantuvo igual?». Esta segunda pregunta iba seguida por una abierta en la que se le preguntaba el porqué de la categoría elegida. Veamos los resultados en nuestra población objeto de estudio. La mitad considera que su grado de práctica es medio; casi un tercio considera que su grado de práctica es bajo; un 16,2\% afirma que es alto. A su vez, la mitad considera que su práctica religiosa se mantuvo igual en los últimos años; alrededor de un quinto afirma que su práctica disminuyó, y un tercio que creció. Los aspectos sociodemográficos introducen diferencias en el mismo sentido que para las prácticas religiosas. Las mujeres se perciben más practicantes que los varones y consideran más que ellos que su práctica creció en los últimos años. Lo mismo sucede con las personas de más edad respecto de los otros grupos etarios, y para los nacidos en los países limítrofes respecto de los nacidos en el AMBA.

Resumiendo, puede afirmarse que para la mitad de la población la práctica religiosa es un aspecto estable en sus vidas, y a su vez, también una mitad percibe que tiene un grado de práctica medio. En rigor, observando el cruce de ambos aspectos 
— ver cuadro 6 para seguir el análisis de este párrafo-, la situación de percibir que su práctica se mantuvo estable y que su grado de práctica es medio comprende a poco más de un cuarto de la población, grupo mayoritario dentro de las nueve combinaciones posibles entre ambos aspectos. De este grupo podría inferirse que la religión pareciera acompañar «naturalmente» sus vidas: es un componente del ciclo de sus actividades y de su mundo simbólico. Es interesante que, dentro de los que afirman que su grado de práctica se mantuvo igual, algunos afirman que la perciben como alta $(5,7 \%$ del total de la población), pudiendo inferirse que está compuesto por quienes mantienen a lo largo de sus vidas un fuerte compromiso con lo religioso, y otro grupo que manifiesta que su grado de práctica es bajo $(14,9 \%$ del total), de lo que se infiere que son las personas que en forma estable se vinculan en forma distante con la esfera religiosa. En el otro extremo, el grupo que percibe que su práctica religiosa creció y a su vez esta es alta, comprende a casi el 10\% de la población, y el grupo que afirma que disminuyó y que esta es baja comprende a otro $10 \%$ de la población total. Estos dos últimos grupos evidencian que en proporciones iguales hay personas para quienes lo religioso tiene un peso creciente, y personas para quienes este peso va disminuyendo (cuadro 6).

\section{Cuadro 6. Percepción sobre el grado de práctica acerca de su evolución (porcentajes)}

\begin{tabular}{lcccc}
\hline \multirow{2}{*}{$\begin{array}{l}\text { Percepción sobre el grado } \\
\text { de práctica }\end{array}$} & \multicolumn{2}{c}{ En los últimos ańos, su práctica religiosa... } & \multirow{2}{*}{ Total } \\
\cline { 2 - 4 } & Creció & Se mantuvo igual & Disminuyó & \\
\hline Alto & $\mathbf{9 , 8}$ & $\mathbf{5 , 7}$ & $\mathbf{1}$ & 16,5 \\
Medio & $\mathbf{1 6}$ & $\mathbf{2 7 , 6}$ & $\mathbf{1 1 , 6}$ & 55,2 \\
Bajo & $\mathbf{3 , 9}$ & $\mathbf{1 4 , 9}$ & $\mathbf{9 , 5}$ & 28,4 \\
Total & 29,6 & 48,2 & 22,2 & 100 \\
\hline
\end{tabular}

Fuente: Procesamientos propios a partir de la encuesta sobre la presencia religiosa en asentamientos 2014 - UCA. 400 entrevistados. Publicado en Suárez, 2015, p. 101.

¿Cuáles fueron las expresiones de las personas ante la pregunta con respecto a por qué su práctica religiosa había crecido, se había mantenido igual o había disminuido? Entre quienes afirmaron que su práctica creció (casi un tercio de la población) las respuestas van en diferentes sentidos. Estas destacan aspectos de la creencia, de las prácticas, del apoyo de la comunidad, de la fe en los milagros; se vinculan asimismo con atravesar situaciones dolorosas, con lo que globalmente hemos denominado espiritualidad, y por último, con el nombramiento de Bergoglio como papa. El cuadro 7 consigna respuestas dadas - tal cual fueron expresadas por las personas - que ejemplifican cada una de las dimensiones mencionadas. Las respuestas que hemos englobado 
como "prácticas y participación» son muchas, porque ejemplifican la diversidad de prácticas mencionadas (rezar, asistir al culto, leer la Biblia, confesarse, etc.).

Entre quienes manifestaron que su práctica religiosa se mantuvo igual (la mitad de la población), la variedad de tipo de respuestas es menor que en el grupo anterior. La mayoría tendió a dar respuestas que de una u otra forma afirmaban que nada en su práctica y en su fe había cambiado. Algunos reportaron un tema de falta de tiempo como argumento. Las respuestas que ejemplifican las situaciones mencionadas están en el cuadro 7.

Aquellos que expresaron que su práctica religiosa disminuyó (22,1\% de la población) vinculan sus respuestas principalmente con temas de práctica y participación, la falta de fe, falta de tiempo, carencia de motivación y el efecto de situaciones dolorosas. Es de destacar que solo en este grupo aparecen cuestiones vinculadas con lo moral, o sea, a conciencia de estar alejado de los parámetros morales fijados por la religión a la que se adhiere. Las respuestas para cada dimensión se ejemplifican en el cuadro 7.

Cuadro 7. ¿Por qué en los últimos años considera que su práctica religiosa creció, se mantuvo igual o disminuyó? Respuestas agrupadas por dimensiones

\begin{tabular}{|c|c|}
\hline $\begin{array}{l}\text { Por qué creció la práctica } \\
\text { religiosa }\end{array}$ & Frases de los encuestados que ejemplifican \\
\hline Creencia & $\begin{array}{l}\text { Porque creo más en Dios, en la virgen y en los santos. } \\
\text { Porque creo cada día en Dios. }\end{array}$ \\
\hline Prácticas y participación & $\begin{array}{l}\text { Participo más de las actividades eclesiásticas. } \\
\text { Porque antes no iba a la iglesia, ahora sí, poco, pero voy. } \\
\text { Porque empecé a leer la Biblia y como que creo más en Dios. } \\
\text { Porque me confirmé. } \\
\text { Porque no rezaba a la noche, ahora sí. } \\
\text { Últimamente voy porque me gusta a mí y cuando voy a la Iglesia } \\
\text { siento paz y tranquilidad. }\end{array}$ \\
\hline Apoyo de una comunidad & $\begin{array}{l}\text { Conocí gente que me acompaña y apoya, y siento que Dios me escucha. } \\
\text { Porque me acerqué al grupo de jóvenes de la parroquia. }\end{array}$ \\
\hline Milagros & $\begin{array}{l}\text { Crecí más por los milagros. } \\
\text { Por el milagro concedido. }\end{array}$ \\
\hline El dolor & $\begin{array}{l}\text { Hace dos años que tengo un hijo con ataques de epilepsia, eso me } \\
\text { acercó a Dios. } \\
\text { La muerte de mi hijo me ayudó a acercarme a Dios. }\end{array}$ \\
\hline Rehabilitación & $\begin{array}{l}\text { Antes cuando consumía droga le daba poca importancia a Dios; } \\
\text { ahora sin el consumo le doy más. }\end{array}$ \\
\hline Espiritualidad & $\begin{array}{l}\text { Uno con el tiempo crece espiritualmente. } \\
\text { Antes había perdido y ahora me volvió la esperanza. } \\
\text { Con el pasar del tiempo cada vez me acerco más a Dios. } \\
\text { Porque busco más de Dios y ahora que lo busco más, lo conozco mejor. }\end{array}$ \\
\hline $\begin{array}{l}\text { El nombramiento del papa } \\
\text { Francisco }\end{array}$ & Por el papa. \\
\hline
\end{tabular}




\begin{tabular}{|c|c|}
\hline Por qué se mantuvo igual & Frases que ejemplifican \\
\hline $\begin{array}{l}\text { Expresiones que afirman que } \\
\text { no registra cambios }\end{array}$ & $\begin{array}{l}\text { No cambió en nada. } \\
\text { No me acerqué ni me alejé de la religión. } \\
\text { Porque llego al punto límite, tengo una creencia que de allí no baja } \\
\text { ni sube. } \\
\text { Es como cotidiano. Siento que está bien lo que hago. }\end{array}$ \\
\hline Prácticas & $\begin{array}{l}\text { No voy a la iglesia seguido ni siento ningún cambio. } \\
\text { Porque hace ańos asisto a misas solo los domingos cuando puedo. } \\
\text { Hago lo mismo de siempre, voy de vez en cuando a misa. } \\
\text { Siempre hago lo mismo, no rezo mucho, solo en casos especiales } \\
\text { (cuando alguien está enfermo). }\end{array}$ \\
\hline $\begin{array}{l}\text { Fe y práctica } \\
\text { Porque la fe siempre está. }\end{array}$ & $\begin{array}{l}\text { Porque me mantengo igual con mi fe. Si no voy a la iglesia, rezo en } \\
\text { mi casa. }\end{array}$ \\
\hline Falta de tiempo & $\begin{array}{l}\text { Porque le dedico a Dios el tiempo que puedo } \\
\text { Porque siempre la misma rutina, por el trabajo, los chicos, no se } \\
\text { puede. } \\
\text { Falta de tiempo. }\end{array}$ \\
\hline Por qué disminuyó & Frases que ejemplifican \\
\hline $\begin{array}{l}\text { Prácticas relevadas } \\
\text { y participación }\end{array}$ & $\begin{array}{l}\text { Antes iba mucho y ahora no. } \\
\text { No concurro a la iglesia, creo en Dios pero no lo practico. } \\
\text { Porque antes iba tres veces por año y ahora voy una vez al año. } \\
\text { Porque antes iba, participaba de todo y ahora no hago mucho por } \\
\text { los demás. } \\
\text { Porque dejé de asistir. } \\
\text { Porque no me acerqué a la Iglesia (solo para el bautismo de mi hija) } \\
\text { le di poca importancia. No me acerqué a la religión, no me llamó la } \\
\text { atención }\end{array}$ \\
\hline $\mathrm{Fe}$ & Porque no tengo tanta fe como antes \\
\hline Falta de motivación & No nace de mí la intención de ir a la iglesia \\
\hline Falta de tiempo & $\begin{array}{l}\text { A veces no tengo ganas ni tiempo, mi pareja no me acompaña } \\
\text { Falta de tiempo. } \\
\text { Mucho trabajo, cansancio. }\end{array}$ \\
\hline Situaciones dolorosas & Al fallecer mi mamá. \\
\hline Cuestiones morales & $\begin{array}{l}\text { Por las tentaciones carnales. } \\
\text { Porque ahora oro menos, aunque vengo muy seguido a la iglesia } \\
\text { (evangélica). Elegí algunas cosas de este mundo. Además, digo que } \\
\text { mi práctica es media porque no soy santo. No soy justo ni santo. }\end{array}$ \\
\hline Otras razones & Porque tengo problemas con las drogas \\
\hline No sabe & No sé decir muy bien por qué \\
\hline
\end{tabular}

Fuente: Procesamientos propios a partir de la encuesta sobre la presencia religiosa en asentamientos 2014 - UCA. 


\section{ConClusiones}

Adentrarse en las prácticas religiosas de las personas ayuda a comprender cómo viven y expresan su fe, o sea, la forma en que las personas se vinculan con lo sagrado, la manera en que mantienen activas sus creencias, los rituales por los cuales sus devociones y vivencias religiosas se conservan, se alimentan y se significan. Desde esta aproximación, tejida en el cruce de los abordajes sintetizados en las metáforas del Entre-medio y de la Otra lógica buscamos adentrarnos en las prácticas religiosas de residentes en espacios de alta marginalidad urbana. Destacamos a manera de conclusión del trabajo algunos aspectos.

Primero, que el espectro de prácticas religiosas es amplio; sus contenidos, espacios y ritualidad son muy variados. Que el ranking de prácticas religiosas efectuadas al menos una vez en el año, tanto por autoafiliados católicos como evangélicos, esté liderado por dos que apuntan a espacios y modalidades muy distintas (orar en la casa y asistir a la ceremonia de su culto) puede leerse como evidencia de que, efectivamente, en la orquestación del vínculo con lo sagrado lo institucional y lo personal se complementan, afirmación que posiblemente pueda hacerse también para el resto de las prácticas. La práctica de la promesa y la de sacralizar los espacios domésticos a través de altares vinculan con dimensiones que creemos remiten a aspectos de una religión «vivida» en la que confianza, entrega, obligación, conmemoración se imbrican con lo religioso. Ambas — promesa y altar doméstico- vinculan prácticas con devociones religiosas y se caracterizan por la carga de respeto o admiración hacia figuras sagradas. Remiten, por tanto, a dimensiones que combinan lo cosmológico y holístico, condensando la densidad de un entramado en el que lo trascendente e inmanente se fusionan en un orden donde el tipo de accionar humano marca el curso de las energías. Estas prácticas, por tanto, se nutren de la simbología y del lenguaje religioso, pero van «más allá»: conectan con lo sagrado o trascendente, y lo hacen sobre un fuerte sustrato corporal, vivencial y emocional.

El trabajo evidenció, asimismo, que, aun si con una incidencia baja, ciertas prácticas religiosas típicas de la tradición católica (por ejemplo, recibir a la virgen en la casa, peregrinar, etc.) son efectuadas por autoafiliados evangélicos, y viceversa, hay católicos que realizan prácticas religiosas del espectro evangélico. Personas sin afiliación, asimismo, reconocen haber participado de algún ritual religioso. ¿Cómo leer estos datos? Desde abordajes cuantitativos es difícil hacerlo; la información merecería ahondarse con análisis que se adentren en el significado que para estas personas tiene el mundo religioso. Cabe sí resaltar de lo evidenciado en nuestro análisis que este dato puede ser leído como un indicador de porosidad entre adscripciones religiosas; de fronteras flexibles y borrosas entre pertenencias religiosas.

Otro aspecto a destacar del trabajo es que las prácticas religiosas de la población en villas son efectuadas en su gran mayoría dentro de las fronteras de los barrios 
donde viven. Asistencia al culto, peregrinar, rezar en ermita o santuario, culto de prosperidad o siembra, etc. son prácticas efectuadas en los propios territorios donde habitan. De hecho, las villas se caracterizan por ser espacios muy marcados por lo religioso. Cualquiera que haga un recorrido rápido por los barrios precarios de la ciudad advierte la cantidad y variedad de expresiones «religiosas» que los atraviesan. Fiestas, procesiones, celebraciones varias, acompañan la vida cotidiana a lo largo del ańo. A su vez, la dinámica y el ciclo religioso se cristaliza en lugares de culto y en marcas religiosas que surcan el espacio público. Cabe así una reflexión sobre la relación entre práctica religiosa y territorio.

Siguiendo la argumentación de Rita Segato (2008, p. 46), entre otros, la identidad no es generada porque se comparta un territorio común, sino que es ella la que genera e instaura el territorio. La diversidad de pertenencias religiosas de la población en villas de CABA, su fuerte movilidad y porosidad, la variedad de prácticas religiosas, la fluidez de intercambios dentro del mundo religioso, y entre este y el político social, son aspectos que van marcando la «identidad» del territorio, dándole dinámicas y matices propios. Lo interesante es que esta «vitalidad» religiosa se conjuga con otra contrapuesta, que es el aislamiento en que los habitantes de estos territorios tienden a vivir en relación con el resto de la ciudad; cierta guetificación que redunda en que las interacciones sociales tiendan a darse entre ellos. Variedad de expresiones de fe, fluidez y fronteras borrosas, por un lado, y de aislamiento y poca integración, por otro, son coordenadas por las cuales los sectores urbanos más marginados que habitan el territorio van construyendo su propia identidad religiosa, su mundo simbólico y su matriz de sentidos ${ }^{17}$. Mundo simbólico y «territorio» que su vez se va reconfigurando y ampliando por el consumo de los productos culturales ofrecidos a través de los medios de comunicación y el acceso a internet. La práctica religiosa sostenida por estos medios suscita una serie de preguntas, dejando abierto un interesantísimo espacio de indagación.

Finalmente, cabe destacar, por lo analizado en relación con la autopercepción de la práctica religiosa, que la mayoría se ubica en situaciones intermedias de las dos dimensiones analizadas (grado y cambio). La lectura que sugerimos de este dato es que pareciera que la práctica religiosa acompañase «naturalmente» las vidas de los habitantes de las villas, que es un componente del ciclo de sus actividades y de su mundo simbólico.

17 Cabría también una breve reflexión sobre la relevancia que tiene el hecho de que las instituciones religiosas (los lugares de culto) estén dentro de las fronteras de los lugares donde viven las poblaciones marginales. Creemos que no son instituciones indiferentes en la vida de las villas. Sus propuestas, discursos, orientaciones, servicios, actividades, etc. gravitan en las condiciones de vida y en el mundo simbólico de los pobladores. La movilidad entre los lugares de culto ante disconformidad o ante mejores «ofertas» tiende a ser dentro de los límites del barrio. Este argumento contribuye a comprender la fuerte flexibilidad tanto en la afiliación como en la práctica religiosa de los residentes en villas. 


\section{REFERENCIAS BIBLIOGRÁFICAS}

Algranti, J. (2011). La religión como cultura material: sociogénesis de los circuitos editoriales en el mundo católico y evangélico. Horizontes antropológicos, 17(36), 67-93. https://doi.org/10.1590/S0104-71832011000200004

Algranti, J. (2013). La industria del creer. Sociología de las mercancías religiosas. Buenos Aires: Biblos.

Ameigeiras, A. (2008). Religiosidad popular. Creencias religiosas populares en la sociedad argentina. Buenos Aires: Biblioteca Nacional-UNGS.

Assman H. (1987). La iglesia electrónica en América Latina. San José de Costa Rica: DEI. Recuperado de https://archive.org/details/laiglesiaelectro00assm

Carranza, B. (2011). Catolicismo midiático. São Paulo: Idéias \& Letras.

Carranza, B. (2015). Desafios à imaginação da pastoral urbana: uma pesquis. En V. H. Mendes (ed.), Evangelización en las culturas urbanas. Memorias y compromisos en América Latina y el Caribe. Bogotá: Centro de Publicaciones CELAM.

De la Torre, R. (2012). La religiosidad popular como "entre-medio» entre la religión institucional y la espiritualidad individualizada. Civitas, 12(3), 506-521. https://doi. org/10.15448/1984-7289.2012.3.13013

Drescher, E. (2011). Tweet if you Heart Jesus: Practicing Church in the digital Reformation. Nueva York: Morehouse Publishing.

Fausto Neto, A. (2006) As estratégias midiáticas da religiosidade contemporânea. Recuperado el 25/3/2015 de http://www.ihu.unisinos.br/noticias/noticias-anteriores/3553-asestrategias-midiaticas-da-religiosidade-contemporanea-entrevista-especial-comantonio-fausto-neto

Haesbaert, R. (2004). O mito da desterritorializaçao. Do «fin dos territorios» à multiterritorialidade. Río de Janeiro: Bertrand.

Mallimaci, F. (2013). Atlas de las creencias religiosas en la Argentina. Buenos Aires: Biblos.

Martín, E. (2007). Aportes al concepto de religiosidad popular: revisión de la bibliografía argentina. En M. J. Carozzi y C. Cernedas (coords.), Ciencias sociales y religión en América Latina. Perspectivas en debate. Buenos Aires: Biblos-ACSRM.

Martín-Barbero, J. (1995). Secularizacion, desencanto y reencantamiento massmediático. Diálogos de la Comunicación, 41, revista de la Federación Latinoamericana de Facultades de Comunicación Social. Medellín. Recuperado de https://rolandoperez.files.wordpress. com/2009/02/secularizacion-reencantamiento-y-desencantamiento-massmediatico-jmartin-Martín-Barbero.pdf

Martino, L. M. S. (2014). A pesquisa em mídia e religião no Brasil: articulaçôes teóricas na formação de uma área de estudos. Revista Comunicaçao \& Inovacao. São Paulo: Universidade Municipal de São Caetano do Sul https://doi.org/10.13037/ ci.vol15n29.2791

McLuhan, M. (1972). La Galaxia Gutenberg. Madrid: Aguilar.

Muniz Souza, B. (1969). Experiência da salvação:pentecostais em São Paulo. São Paulo: Duas Cidades. 
Parker, C. (1993). Otra lógica en América Latina. Religión popular y modernización capitalista, Santiago de Chile: Fondo de Cultura Económica.

Pérez, R. (2012). Representaciones y mediatizaciones públicas de la religión. Conexión Pontificia Universidad Católica del Perú. Lima: PUCP. Recuperado de https://rolandoperez.files.wordpress.com/2012/11/conexic3b3n.pdf

Sbardelotto, M. (2014). La reconstrucción de lo religioso en la circulación en redes sociodigitales. La trama de la comunicación, 18(2), 151-170. Recuperado el 02/02/2015 de http://www.scielo.org.ar/pdf/trama/v18n2/v18n2a01.pdf de

http://www.scielo.org.ar/pdf/trama/v18n2/v18n2a01.pdf

Segato, R. L. (2008). La faccionalización de la república y el paisaje religioso como índice de una nueva territorialidad. En A. Alonso (comp.), América Latina y el Caribe. Territorios religiosos y desafíos para el diálogo (pp. 41-81). Buenos Aires: Clacso.

Semán, P. (2001). Cosmológica, holista y relacional: una corriente de la religiosidad popular contemporánea. Ciências Sociais e Religião, 3(3), 45-74.

Sen, A. (2000). Desarrollo y libertad. Madrid: Planeta.

Souza, A. (2005). Igreja in concert. São Paulo: Annablume.

Suárez, A. L. (2016). Devociones, promesas y milagros. Aproximación a dimensiones de la espiritualidad en sectores populares. Ciencias Sociales y Religión / Ciências Sociais e Religião, 18(24), 54-70. https://doi.org/10.22456/1982-2650.57841

Suárez, A. L. (dir.) (2015). Creer en las villas. Devociones y prácticas religiosas en los barrios precarios de la ciudad de Buenos Aires. Buenos Aires: Biblos.

Suárez, A. L., Mitchell, A. y Lépore, E. (eds.) (2014). Las villas de la ciudad de Buenos Aires. Territorios frágiles de inclusión social. Buenos Aires: Educa. 